\title{
Variations in the Mycorrhization Characteristics in Roots of Wild-Type and ABA-Deficient Tomato Are Accompanied by Specific Transcriptomic Alterations
}

\author{
José Manuel García Garrido, Rafael Jorge León Morcillo, José Ángel Martín Rodríguez, and \\ Juan Antonio Ocampo Bote \\ Departamento de Microbiología del suelo y sistemas simbióticos, Estación Experimental del Zaidín, CSIC, Calle Profesor \\ Albareda no. 1, 18008 Granada, Spain
}

Submitted 3 November 2009. Accepted 20 January 2010.

\begin{abstract}
Abscissic acid (ABA) determines mycorrhiza functionality and arbuscule development. In this study, we performed transcriptome analysis in response to different mycorrhization status according to the ABA content in the root to identify genes that may play a role in arbuscule functionality. Affymetrix Tomato GeneChip (approximately 10,000 probes) allowed us to detect and compare the transcriptional root profiling of tomato (Solanum lycopersicum) wild-type and ABA-deficient sitiens plants colonized by Glomus intraradices. A number of identified genes in tomato belong to a category of genes already described as "mycorrhizal core-set" in other host plants. The impairment in arbuscular mycorrhiza (AM) formation in ABA-deficient mutants was associated with upregulation of genes related to defense and cell wall modification, whereas functional mycorrhization in wild-type plants was associated with activation of genes related to isoprenoid metabolism. The oxylipin pathway was activated in tomato mycorrhizal roots at late stages of interaction, and was related to the control of fungal spread in roots, not with the establishment of the symbiosis. Induction of selected genes, representing a range of biological functions and representative of the three sets of genes specifically upregulated in the different plant phenotype, was confirmed by quantitative reverse-transcription polymerase chain reaction, and their response to phythohormone treatment was tested, showing that ethylene and jasmonic acid are key regulators of gene expression during AM development. Comparative analysis of mycorrhiza upregulated functional categories revealed significant changes in gene expression associated with the different mycorrhization status according to the ABA content in the roots.
\end{abstract}

Arbuscular mycorrhiza (AM) is a symbiotic association of plants and arbuscular mycorrhizal fungi and involves fungi from the Glomeromycota group and the majority of vascular flowering plants. The establishment of the AM mutualistic association is a successful strategy to improve the nutritional status of both partners (plant and fungus). The efficiency of the symbiosis is mainly due to the development of an extensive and

Corresponding author: J. M. G. Garrido; Telephone: +34 958181600 (ext. 145/302); Fax: +34 9581296 00; E-mail: josemanuel.garcia@eez.csic.es

* The $\boldsymbol{e}$-Xtra logo stands for "electronic extra" and indicates that three supplementary figures and three supplementary tables are published online. branched fungal hyphal network outside the roots that efficiently uptakes mineral nutrients (principally phosphorous) which are transferred to plant cortical cells by specialized intraradical, highly branched structures named arbuscules. In return, the plant provides the fungus with carbohydrates.

The key to understanding the phenomenon of compatibility between fungus and plant in the AM association is the elucidation of the recognition mechanisms and molecules involved in the AM interaction. In this respect, there have been significant and relevant discoveries regarding the signaling associated with the development of AM symbiosis. Recently, progress has been made regarding the molecular mechanisms of communication between plants and fungi at the early stages of AM development, and a group of compounds (strigolactones) that exude from the plant root has been identified and characterized as inducers of hyphal branching of AM fungi (Akiyama et al. 2005). Moreover, a symbiotic plant signal-transduction cascade is activated in plant roots after both rhizobia and AM fungi recognition by plant root (Parniske 2004, 2008). Orthologs of the symbiotic genes cloned in legumes have been identified in a number of dicotyledons and monocotyledons, and the function of these genes appears to be conserved between rice and legumes (Godfroy et al. 2006; Chen et al. 2007, 2008; Banba et al. 2008). In addition, an alternative AM-specific but symbiotic independent pathway was identified in rice (Gutjahr et al. 2008).

Despite the recent progress in signaling events, knowledge of processes required for AM formation is still limited. In the last few years, a number of transcriptome analyses have been performed to identify genes controlling intraradical AM formation. A variety of transcript profiling approaches in different plant species have illustrated the changes that occur in plant roots upon mycorrhizal colonization. In the case of rice, the results demonstrate the existence of a group of genes that are exclusively AM induced but also a group of genes that are similarly expressed in symbiotic and pathogenic fungal associations, suggesting a conserved mechanism of plant adaptation to fungal colonization (Güimil et al. 2005). A mycorrhiza core set of genes has been identified in Medicago truncatula (Hohnjec et al. 2005; Liu et al. 2007), and common transcriptional induction has been demonstrated in Lotus japonicus and M. truncatula (Guether et al. 2009), reflecting substantial evolutionary conservation responses to AM colonization. However, the existence of studies that failed to identify some common symbiotic gene markers (Deguchi et al. 2007) suggests some divergence in the symbiotic programs between plant species. Three transcriptome analyses have focused on the identification of genes expressed 
in cortical cells containing arbuscules (Fiorilli et al. 2009; Gomez et al. 2009; Guether et al. 2009). In all cases, the use of laser microdissection methodology coupled with transcript profiling analysis has enabled the identification and confirmation of transcript location in arbusculated cells for a set of genes from M. truncatula (Gomez et al. 2009), L. japonicus (Guether et al. 2009), and tomato (Fiorilli et al. 2009). Recently, Grunwald and associates (2009) compared transcriptome changes and overlapping expression pattern in $M$. truncatula roots under Pi fertilization, AM, or by phytohormone abscissic acid (ABA) and jasmonic acid (JA) treatment. These authors found that there is no considerable overlap between hormone treatment and colonization, and also showed not much overlap between Gigaspora and Glomus spp. colonization in terms of transcript changes (Grunwald et al. 2009).

The arbuscule is the symbiotic structure for nutrient transfer in AM and, in several studies, it has been shown that their development and functionality are related to phytohormone pathways, such as JA and ABA pathways (Isayenkov et al. 2005; Herrera-Medina et al. 2007). Experiments using genetic approaches have shown that the plant hormone ABA plays a role in the establishment of a functional AM symbiosis. The analysis of the AM colonization in the tomato mutant sitiens, in which ABA levels are reduced to only $8 \%$ of those in wildtype tomato plants (Herde et al. 1999), has shown that ABA is necessary for arbuscule functionality and for a sustained colonization of the plant root (Herrera-Medina et al. 2007). Sitiens plants are less susceptible to AM fungi infection, and the parameters of mycorrhization are reduced by approximately $70 \%$ compared with wild-type plants (Herrera-Medina et al. 2007). Furthermore, the majority of the arbuscules in these mutant plants are arbuscules with no fine branches that only partially occupy the plant cell, suggesting that incomplete arbuscule development could occur in these plants (HerreraMedina et al. 2007).

In view of the importance of ABA in AM formation, and given the existence of an Affymetrix GeneChip for this plant species, we performed a microarray analysis comparing mycorrhizal tomato roots of wild-type and ABA-deficient mutant plants to obtain an overall view on genome-wide transcript modification in response to different mycorrhization status according to the ABA concentration in the root. Clear differences in gene functional categories between mycorrhizal wildtype and ABA-deficient mutants were obtained. Our microarray results allowed us to select a number of genes related to AM symbiosis functionality, some of them responsive to phytohormones.

\section{RESULTS}

\section{Microarray analysis of gene expression according to the $A B A$ content in the root.}

The aim of this investigation was to analyze transcriptomic changes associated with AM formation and ABA content in tomato roots. Previous experiments revealed that sitiens ABAdeficient mutants failed to form AM fungi infection, and the parameters of mycorrhization in these mutants were reduced by approximately $70 \%$ compared with wild-type plants (Herrera-Medina et al. 2007). Here, we performed three independent experiments of mycorrhization of wild-type and sitiens plants (Supplementary Table S1). Each experiment constitutes a biological replica with four treatments (Rheinlands Ruhm and sitiens plants, inoculated and uninoculated with Glomus intraradices). RNA from a pool of three root samples was isolated per treatment and labeled to hybridize the Affymetrix Tomato GeneChip that contains 10,209 probe sets. In total, 12 experiments of chip hybridization were performed. We also performed a microarray comparison on nonmycorrhizal wildtype and sitiens roots to exclude indirect effects of the differing ABA levels in gene expression, because the extent of induction or repression of gene expression due to mycorrhizal colonization may depend on transcript levels of the respective gene in nonmycorrhizal roots.

Plants were harvested 50 days after inoculation because previous studies have shown clear differences in mycorrhization parameters at this time (Herrera-Medina et al. 2007). The measurement of mycorrhization parameters showed that wildtype plants in all experiments had a high percentage of colonization intensity and arbuscule abundance whereas sitiens plants appeared to be less susceptible, with a considerable decrease in both parameters (Supplementary Fig. S1). To check arbuscule functionality in sitiens roots, quantitative reverse-transcription polymerase chain reaction (qRT-PCR) experiments of LePT4 gene expression were carried out with cDNA from wild-type and sitiens plants (Supplementary Fig. S2). In all experiments, the level of LePT4 gene expression was higher in wild-type roots inoculated with $G$. intraradices than in inoculated sitiens roots. As we expected, ABA levels in root of sitiens plants were reduced compared with those in wild-type tomato plants, and the ethylene production was enhanced in ABA-deficient tomato mutants.

Differentially expressed genes were identified by the following criteria: more than twofold change (inoculated/un-inoculated) in expression level applying a $P$ value $<0.05$. Using these criteria, the number of selected genes was 238 (Supplementary Table S2). Of these, 127 showed increased transcript levels in wild-type tomato $G$. intraradices-colonized roots, and 50 genes showed decreased transcript levels in the same roots. In sitiens roots, 98 genes were found to be differentially expressed, 83 up- and 15 downregulated in mycorrhizal plants compared with noninoculated plants. The two data sets (wildtype versus sitiens) showed an overlap. From the overlapping genes, 33 of them (13\% of the total of selected genes) were found to be upregulated both in wild-type and sitiens mycorrhizal plants (common Myc upregulated genes) and only 4 genes ( $2 \%$ of the total selected genes) were downregulated in mycorrhizal roots independently of the plant phenotype (common Myc downregulated genes). The data distribution of the selected genes according to plant genotype showed that a set of genes was specifically and differentially up- (40\%) or downregulated $(19 \%)$ in wild-type and up- $(22 \%)$ or downregulated (4\%) in ABA-deficient mutant roots in response to AM formation (Supplementary Fig. S3).

\section{Annotation, putative identification, and molecular function assignment.}

With the information from the Affymetrix Tomato GeneChip and from BLAST analysis in the Solanaceae Genomics Network (SGN) tomato expressed sequence tag database at the University of Cornell, we were able to identify or assign putative molecular function to the selected genes.

As in other mycorrhizal host plants, we identified in tomato putative orthologs of genes which have already been described as "mycorrhizal core-set" (Liu et al. 2007; Guether et al. 2009). Similar to M. truncatula (Liu et al. 2003) and L. japonicus (Kistner et al. 2005), we found that protease genes of tomato are highly regulated in mycorrhizal roots. Among these genes from protein catabolism, two fall under the category of subtilisin-like proteases (Les.5764.1.S1_at and LesAffx.8850.1. S1_at); one was a serine-carboxypeptidase (Les.4810.1.S1_at) and the other was a putative miraculin protease (Les.3397.1. $\mathrm{S} 1 \_$at). Interestingly, all of these protease genes were mycorrhiza upregulated similarly in wild-type and sitiens plants, except a putative subtilisin protease that was found to be up- 
regulated only in mycorrhizal sitiens plants (Les.513.1.S1_at). Two putative protease-inhibitor genes were found upregulated in wild-type mycorrhizal roots (Les.3281.1.S1_at and Les. 4820. 1.S1_x_at) and two were found upregulated exclusively in mycorrhizal sitiens plants (LesAffx.69210.1.S1_at and Les.3940.2.A1_at). Other genes from the mycorrhiza core-set, such as genes which encode a glucoxyltransferase, an annexin, an aquaporin-like protein, a cytochrome P450, a gibberellin 20-oxidase, or an glutathione S-transferase, were mycorrhiza upregulated genes mainly associated with wild-type plants.

Based on the putative molecular function of the selected genes, we classified them into the following functional categories: metabolism (includes protein, lipid, carbohydrate, primary, and secondary metabolism), transport, signaling, phytohormone metabolism (phytohormone synthesis), defense and stress response, cell-wall relative, and "others" (including unclassified or unknown function proteins). The comparative analysis of functional categories of mycorrhiza upregulated genes is shown in Figure 1. A similar picture between common and wild-type specific upregulated genes was found. The categories of metabolism, transport, and signaling and phytohormone metabolism were similarly represented in the common- and wild-type-specific mycorrhiza upregulated sets, though the majority of the common- and wild-type-specific mycorrhizaupregulated genes seem to be related to metabolic changes associated with mycorrhization in tomato roots. The second largest functional category of the common mycorrhiza-upregulated set of genes was the category related to defense and stress response that represented $15 \%$ of the total of common upregulated genes. In the group of genes upregulated only in mycorrhizal wild-type plants, the category of "others" was the second most abundant. The picture of genes specifically mycorrhiza upregulated in ABA-deficient mutants was completely different. In this case, the largest functional category was "defense and stress" and the representation of genes related to metabolism loses importance in favor of the categories of "cell wall related" and "others." Peculiarly, we observed identical distribution (identical categories and percentages) for mycorrhiza-downregulated genes in wild-type tomato roots as for mycorrhiza-upregulated genes in the same type of plants. In the same way as has been shown for the group of genes specifically upregulated in ABA-deficient mutants, in the group of genes specifically downregulated in ABA-deficient mutants a new category of cell-wall-related genes appeared and the metabolism-related genes were less representative (Fig. 1).

\section{qRT-PCR analysis of representative genes.}

qRT-PCR analysis was carried out to verify the array hybridization data. The qRT-PCR reactions used RNA from inoculated and uninoculated plants from experiments I and II that were used as independent biological replicates from the microarray analysis. qRT-PCR assays were performed on 14 selected genes, representing a range of biological functions and representative of the three sets of genes upregulated in the different plant phenotypes. Of these, seven were found to be upregulated in both wild-type and sitiens mycorrhizal plants, three genes showed increased transcript levels only in wild-type plants, and four were exclusive for mycorrhizal sitiens roots (Table 1).

\section{Comparative analysis}

with tomato-G. mosseae mycorrhizal roots.

A previously published transcript profile has shown the transcriptional changes that are triggered in tomato roots and shoots as a consequence of $G$. mosseae colonization (Fiorilli et al. 2009). Using the TOM 2 array probe annotation file from the tomato functional genomics database, we analyzed the overall extent of the overlapping of the 238 Affymetrix probes selected in our experiment on the TOM2 platform. The comparative analysis at the level of SGN unigene identifiers showed that only $47 \%$ of them were present in the TOM2 array. A limited overlap was found when comparing the sequences listed as differently regulated in tomato- $G$. mosseae roots (Fiorilli et al. 2009), obtained from the TOM2 platform, and our selected list of sequences. Compared with the data of Fiorilli and associates (2009), only $15 \%$ of the sequences selected in our experiments had the same SGN unigene identifier in the data of Fiorilli and associates (2009). The data distribution of the overlapping genes according to plant genotype showed that the maximum overlapping $(22 \%)$ was found with the set of genes that exclusively and differentially upregulated in the wild-type tomato plant. The common mycorrhiza-upregulated genes selected in our study showed $18 \%$ of overlapping with genes upregulated in tomato roots colonized by $G$. mosseae, and only 8 and 5\% of overlapping was found with the set of genes upregulated exclusively in the ABA-deficient mutant or downregulated in both kind of plants, respectively. Only six of 34 sequences that overlap have been considered previously as mycorrhiza core set sequences.

Genes involved in defense and cell wall modification are
associated with mycorrhization in ABA-deficient mutant.

The comparative analysis of transcriptomic data obtained in mycorrhizal wild-type and ABA-deficient mutant plants revealed that the impairment in AM formation in ABA-deficient mutants was associated with upregulation of genes related to defense and cell wall modification. Among a total of genes that were found to be upregulated only in mycorrhizal sitiens plants, $30 \%$ belong to the category of disease resistance and stress responses. The upregulated genes belonging to the defense category include five putative peroxidases, two protease inhibitors, three pathogenesis-related proteins, one $\beta-1,3$ glucanase, and one endo-chitinase gene (Table 2).

Although mycorrhization of M. truncatula and L. japonicus increased expression of genes involved in cell wall metabolism, such as endo-1,4 $\beta$-D-glucanase and cellulose synthase genes (Liu et al. 2003; Guether et al. 2009), tomato array analysis revealed that only in the ABA-deficient mutant plants was this functional category of genes differentially regulated. Eleven genes involved in cell wall metabolism were found to be upregulated in ABA-deficient mycorrhizal roots compared with the mycorrhizal wild-type: two endo-1,4 $\beta$-D-glucanase genes, three different pectinase genes, three expansin-related genes, and three putative extensin tomato genes (Table 2). Representative genes for these categories (defense and cellwall modifications) were further tested by qRT-PCR and their induction was confirmed (Table 1).

\section{Functional mycorrhization in wild-type plants is associated with activation of genes directly involved in isoprenoid metabolism.}

Transcriptome analysis revealed upregulation of many genes directly involved in isoprenoid metabolism in wild-type tomato AM, suggesting that a functional and well-established colonization is necessary for their expression in mycorrhizal roots. Among the genes involved in isoprenoid metabolism were the 1-deoxy-D-xylulose 5-phosphate synthase 2 (DXS2) (LesAffx.62488.2.S1_at) and the 1-deoxy-D-xylolose 5-phosphate reductoisomerase $(D X R)$ (Les.3487.1_at) genes which codify for the two enzymes that catalyze the firsts steps of the methylerythritol phosphate (MEP) pathway. The MEP pathway is that used by plastidial to produce isopentenyl diphosphate (IPP) and geranylgeranyl diphosphate (GGDP), from which important plant isoprenoids are derived such as carotenoids, apocarotenoids, ABA, strigolactones, and gibberellins. 
Four genes involved in carotenoid metabolism, including ABA biosynthesis, were found to be upregulated in wild-type mycorrhizal roots compared with mycorrhizal ABA-deficient mutants and the noninoculated control. All of them are potentially involved in apocarotenoids and ABA synthesis, including a phytoene desaturase (Les.259.2.S1_at), a zeta-carotene desaturase (Les.20.1.S1_at), a carotenoid 9,10-9',10' cleavage dioxygenase (Les.5921.1.S1_at), and a putative aldehyde oxidase and xanthine dehydrogenase (Les.3528.1.S1_at) (Fig. 2).

\section{Common mycorrhizal up-regulated genes}

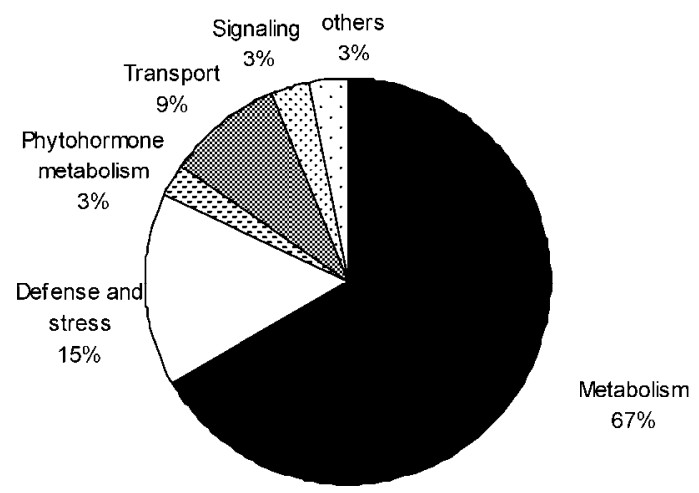

\section{Genes specifically up-regulated in mycorrhizal wild-type plants}

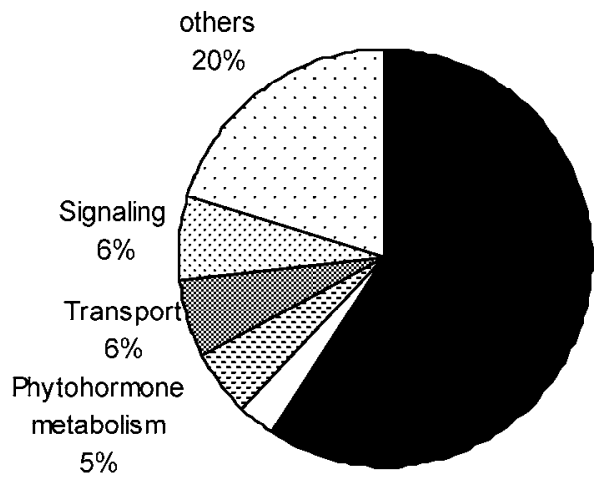

Metabolism $60 \%$

Defense and stress

$3 \%$

\section{Genes specifically up-regulated in mycorrhizal ABA-deficient mutant plants}

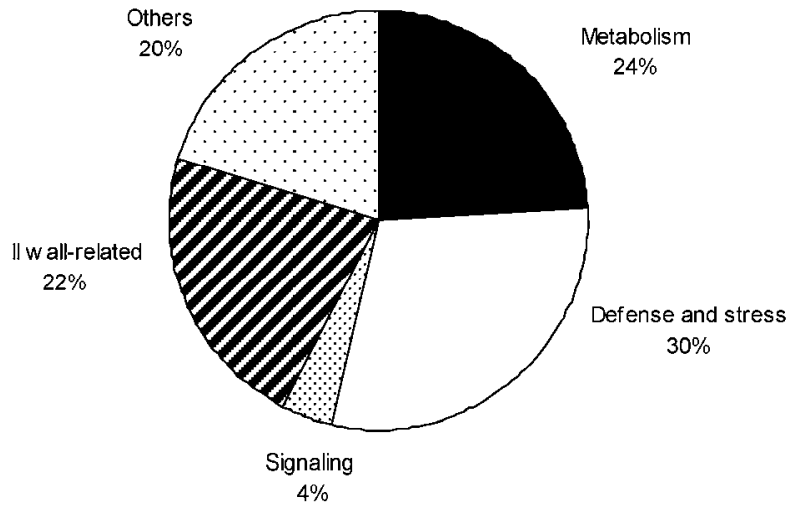

Another group of genes from the data set of specifically upregulated genes in wild-type mycorrhizal roots consists of putative genes related to gibberellin metabolism (Fig. 2). Genes coding for ent-kaurene oxidase (LesAffx.70667.1.S1_at), gibberellin 20-oxidase 1 (Les.64.1S1_at), gibberellin 2- $\beta$-dioxygenase (Les.4335.2.S1_at), and gibberellin 3- $\beta$-dioxygenase (Les.10.1.S1_at) were clearly induced in a functional and wellestablished mycorrhiza in tomato roots. In addition, a gene that encodes a putative copadyl diphosphate synthase (Les.27.1.

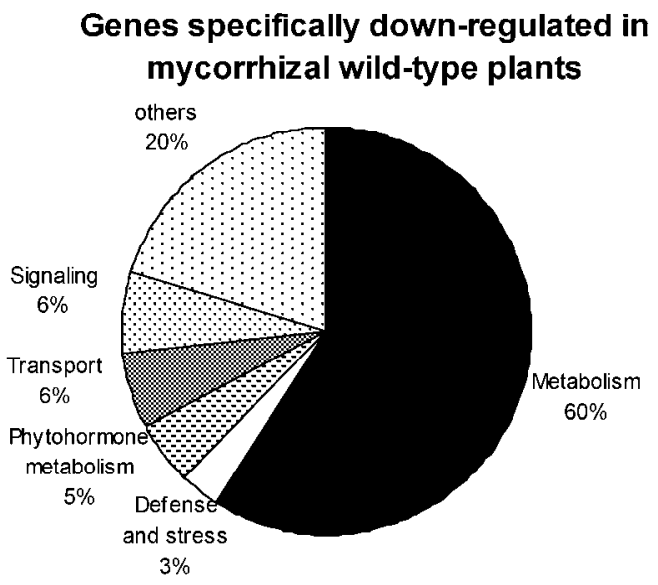

\section{Genes specifically down-regulated in mycorrhizal ABA deficient mutant plants}

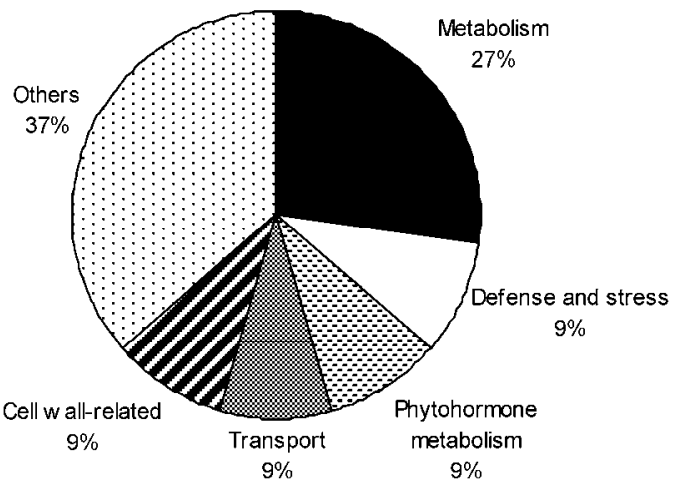

Fig. 1. Pie charts showing the percentage of upregulated and downregulated genes in response to arbuscular mycorrhiza formation in wild type and ABA-deficient sitiens mutant roots of plants harvested 50 days after inoculation with Glomus intraradices. Percentages of genes from the categories of common myc-regulated (regulated in both kinds of plants) and specifically myc-regulated in each plant genotype classified according to functional categories are shown. 
S1_at), which catalyses the first step in gibberellin synthesis from the GGDP precursor, was present in the group of common, upregulated overlapping genes. The value of fold change induction for this gene in the ABA-deficient mycorrizal was 2.09, near the limit of selection criteria.

The regulation of two of these genes associated with carotene and gibberellin synthesis was tested and validated by qRT-PCR. Both genes exhibited strong upregulation upon mycorrhization of wild-type plants (Table 1).

\section{Activation of genes involved in oxylipin metabolism during AM development.}

The arrays analysis performed on mycorrhiza tomato wildtype and sitiens mutants revealed that a set of the upregulated, overlapping genes corresponded to genes involved in oxylipin metabolism. These genes were induced in both wild-type and sitiens plants colonized by $G$. intraradices, suggesting that their induction doesn't require a fully and completely functional AM symbiosis. These included a gene that encodes an

Table 1. Quantitative reverse-transcription polymerase chain reaction (qRT-PCR) validation of genes with differential expression in mycorrhiza wild-type and abscisic acid (ABA)-deficient sitiens mutant ${ }^{\mathrm{a}}$

\begin{tabular}{|c|c|c|c|c|c|c|c|}
\hline \multicolumn{2}{|l|}{ Expressed genes } & \multicolumn{3}{|c|}{ Array data (M value) } & \multicolumn{3}{|c|}{ qRT-PCR (M value) } \\
\hline Tomato Affymetrix ID & Putative annotation & RheI/RheNI & SitI/SitNI & RheI/SitI & RheI/RheNI & SitI/SitNI & RheI/SitI \\
\hline \multicolumn{8}{|l|}{ Common } \\
\hline Les. 3668.1S1_at & Lipoxygenase (LOXA) & 2.2 & 2.8 & -2.2 & $2.3 \pm 0.1$ & $3.2 \pm 0.2$ & $-1 \pm 0.06$ \\
\hline Les. 3986.1.S1_at & Allene oxide synthase (AOS3) & 2.8 & 2.9 & 0 & $4.5 \pm 0.2$ & $4.4 \pm 0.3$ & $2 \pm 0.1$ \\
\hline Les.5934.1.S1_at & $\omega-6$-Desaturase (6-Des) & 2.6 & 2 & -1.2 & $1.3 \pm 0.09$ & $1.8 \pm 0.1$ & $-1 \pm 0.08$ \\
\hline Les.5764.1.S1_at & Protease & 4.5 & 2 & 2.6 & $5.4 \pm 0.4$ & $3.7 \pm 0.27$ & $2.7 \pm 0.2$ \\
\hline Les.51.1.S1_at & RNAse & 4.5 & 1.6 & 3.2 & $6.3 \pm 0.03$ & $2.1 \pm 0.08$ & $3.2 \pm 0.1$ \\
\hline LesAffx.28554.1.S1_at & $\alpha-\beta$ Hydrolase $(\alpha, \beta$ Hydro $)$ & 7 & 2.8 & 3.1 & $9.5 \pm 0.2$ & $5.4 \pm 0.08$ & $4.1 \pm 0.2$ \\
\hline Les.3981.1.S1_at t & UDP-glucosyl transferase (UDP-Glutr) & 6.7 & 2.2 & 4.5 & $7.6 \pm 0.05$ & $2.2 \pm 0.3$ & $6.3 \pm 0.1$ \\
\hline \multicolumn{8}{|l|}{ Wild type } \\
\hline Les.2985.1.A1_at & Oxidoreductase (Oxase) & 4 & 0 & 3.3 & $9.3 \pm 0.1$ & $2 \pm 0.1$ & $6.1 \pm 0.1$ \\
\hline Les.259.2.S1-a-at & Phytoene desaturase (PDS) & 1.5 & 0 & 1 & $1.5 \pm 0.05$ & $1.2 \pm 0.05$ & $0.9 \pm 0.08$ \\
\hline Les.10.1.S1_at & Gibberellin 3- $\beta$-dioxygenase (GA3-ox) & 2.7 & 0 & 2 & $4.9 \pm 0.05$ & $2.4 \pm 0.1$ & $2 \pm 0.1$ \\
\hline \multicolumn{8}{|l|}{ ABA-deficient mutant } \\
\hline LesAffx. 39466.1.S1_at & Peroxidase (Per) & 0 & 2.3 & -1.5 & $1.1 \pm 0.1$ & $3.2 \pm 0.2$ & $-1 \pm 0.05$ \\
\hline Les.513.1.S1._at & Subtilisin (PI-I9) (Subt) & 0 & 3.5 & -2.4 & $0.9 \pm 0.08$ & $2.5 \pm 0.1$ & $-1.7 \pm 0.09$ \\
\hline Les.122.1.S1_at & Endo-Chitinase (Endo-Q) & 0 & 1.7 & -2.3 & $-1.1 \pm 0.07$ & $1 \pm 0.05$ & $-3.1 \pm 0.1$ \\
\hline LesAffx.5130.1.S1_at & $\beta$-Expansine $(\beta$-Exp) & 0 & 2.7 & -2.7 & $-0.7 \pm 0.02$ & $6.1 \pm 0.2$ & $-6.6 \pm 0.03$ \\
\hline
\end{tabular}

${ }^{\text {a }} \mathrm{M}$ value, referring to $\log _{2}$ ratio, is 0 if there is no change and +1 or -1 if there is a twofold induction or reduction, respectively. Data of qRT-PCR M values are means \pm standard error. For qRT-PCR, two biological and three technical replicate experiments were done. Plants were harvested 50 days after inoculation with Glomus intraradices. Rhe = wild-type Rheinlands Ruhm; Sit = sitiens; I = inoculated; NI = noninoculated.

Table 2. Mycorrhizal upregulated genes in the abscisic-acid-deficient mutant (Sit) related to defense and cell wall modification ${ }^{\mathrm{a}}$

\begin{tabular}{|c|c|c|c|c|c|}
\hline \multirow[b]{2}{*}{ Category, ID } & \multicolumn{3}{|c|}{ M value } & \multirow[b]{2}{*}{ Molecular function } & \multirow[b]{2}{*}{ Array ID } \\
\hline & RheI/RheNI & SitI/SitNI & SitI/RheI & & \\
\hline \multicolumn{6}{|c|}{ Defense and stress } \\
\hline BI203178 & 0 & 2.3 & 1.5 & Putative peroxidase & LesAffx.39466.1.S1_at \\
\hline X74906 & 0 & 2 & 1.5 & $\beta, 1-3$ Glucanase TomQ & Les.3652.1.S1_at \\
\hline Z15141 & 0 & 1.7 & 2.3 & Endo-chitinase & Les.122.1.S1_at \\
\hline X70787 & 0 & 1.5 & 1 & PR P23 & Les.45.1.S1_at \\
\hline BI921774 & 0 & 1.5 & 1 & Putative cysteine proteinase inhibitor & LesAffx.69210.1.S1_at \\
\hline AF146690 & 0 & 1.5 & 2 & Pto-responsive gene 1 & Les.3742.1.S1_at \\
\hline U34808 & 0 & 0.3 & 1 & TPSI1. Phosphate starvation induced protein & Les.3614.1.S1_at \\
\hline X71593 & 0 & 1.5 & 1 & CVI1 peroxidase & Les.3608.1.S1_at \\
\hline AJ635323 & 0 & 1.5 & 1 & Polyphenol oxidase A & Les.4527.1.S1_at \\
\hline ВТ013033 & 0 & 1.5 & 1.5 & Peroxidase, prx 14 & Les.4976.1.S1_at \\
\hline CN385433 & 0 & 1.5 & 1.5 & Putative peroxidase, PER72 & LesAffx.39.1.S1_at \\
\hline CN385109 & 0 & 1.5 & 1 & Putative peroxidase & LesAffx.4779.1.S̄1_at \\
\hline BI208926 & 0 & 1 & 1.5 & Putative PR related protein & LesAffx.823.1.S1_at \\
\hline M69248 & 0 & 1.5 & 1 & PR1b1 (p149) & Les.3408.1.S1_at \\
\hline BG628187 & 0 & 1.2 & 1 & Protease inhibitor & Les.3940.2.A1_at \\
\hline \multicolumn{6}{|l|}{ Cell wall related } \\
\hline DQ234354 & 0 & 2.8 & 2.8 & Putative $\beta$-expansin & LesAffx.5130.1.S1_at \\
\hline ВТ014190 & 0 & 2 & 1.5 & Pectate lyase & Les.5579.1.S1_at \\
\hline BG130169 & 0 & 2 & 1.5 & Putative extensin & Les.2946.2.S1_at \\
\hline Z46674 & 0 & 2 & 1 & Extensin Lemmi8 & Les.2839.1.S1_at \\
\hline AF077339 & 0 & 1.5 & 1.5 & Endo-1,4- $\beta$-glucanase (cel5) & Les.3491.1.S1_at \\
\hline AF059489 & 0 & 1.5 & 1.5 & Expansin precursor 5 & Les.369.1.S1_at \\
\hline X55193 & 0 & 1.5 & 1.5 & Similar to pectate lyase & Les.3663.1.S 1 _at \\
\hline AI894578 & 0 & 1.5 & 1.5 & Pectin methylesterase & Les.218.2.S1_at \\
\hline Z46675 & 0 & 1.5 & 1.5 & Extensin (Lemmi11) & Les.3747.1.S1﹎at \\
\hline Y11268 & 0 & 2 & 2.3 & Endo-1,4- $\beta$-D-glucanase & Les.3636.1.S1_at \\
\hline U82123 & 0 & 1.5 & 2 & Expansin (LeEXP1) & Les.191.1.S1_at \\
\hline
\end{tabular}

${ }^{a}$ Data represent the $\mathrm{M}$ value ( $\log _{2}$ ratio), which is 0 if there is no change and +1 or -1 if there is a twofold induction or reduction, respectively. For the array hybridization, three independent biological replicate experiments were done. Rhe $=$ wild-type Rheinlands Ruhm; Sit $=$ sitiens; $\mathrm{I}=$ inoculated; NI = noninoculated.

${ }^{\mathrm{b}}$ Functional category and representative public ID. 
omega-6 fatty acid desaturase (Les.5934.1.S1_at), homolog to Arabidopsis FAD2, which catalyzes the introduction of a carbon-carbon double bond at C-12 in oleic acid (Okuley et al. 1994), forming linoleic acid. Because the dioxygenation of linoleic and $\alpha$-linolenic acids to hydroperoxides is catalyzed by lipoxygenases (LOX), it was not surprising to find that a LOX gene (Les.3668.1.S1_at) was also upregulated in mycorrhizal tomato roots. During the oxylipin pathway in plants, the conversion of hydroperoxides to epoxy octadecatrienoic acids is carried out by allene oxide synthases (AOS), and our array data revealed that one of the AOS genes of tomato (Les.3986.1.S1-at) was also upregulated in mycorrhizal tomato roots, indistinctly from the plant phenotype.

\section{Analysis of gene expression}

at different developmental stages of $\mathrm{AM}$ formation and in response to phytohormone treatment.

qRT-PCR analysis was used to determine the expression pattern of representative genes from the selected pathways during different developmental stages of AM formation and in response to certain phytohormones which have been reported to be implicated in the AM symbiosis formation (Hause et al. 2007).
The expression patterns of selected genes were characterized in roots of wild-type and ABA-deficient sitiens plants at 37 and 56 days, respectively, after inoculation with $G$. intraradices (Fig. 3). In these conditions, the mycorrhization levels were 7.5 and $9.8 \%$ in sitiens and wild-type plants, respectively, at 37 days after inoculation (dai), and $24 \%$ (sitiens) and $48 \%$ (wildtype) of root length colonization at 56 days after fungal inoculation. Endoquitinase (Endo-Q), and subtilisin (PI-I9) genes, which represent the group of genes involved in defense that are associated in the array data with mycorrhization in ABA-deficient mutant, showed a similar expression pattern (Fig. 3A). In inoculated wild-type and sitiens plants, Endo- $Q$ and PI-I9 gene expression was lower than that in noninoculated plants at 37 dai. Gene expression increased only in sitiens-inoculated plant roots from 37 to 56 dai and remained lower in noninoculated and wild-type-inoculated plant roots (Fig. 3A). The expression of the gibberellin 3- $\beta$-dioxygenase $(G A 3-o x)$ gene, related to gibberellin metabolism, was induced in wild-type and sitiens plant roots by mycorrhizal fungal infection at 37 and 56 dai, respectively. An increased expression of GA3-ox from 37 to 56 dai was detected only in wild-type mycorrhizal roots (Fig. 3B), as observed in the array data. Three genes from the oxylipin

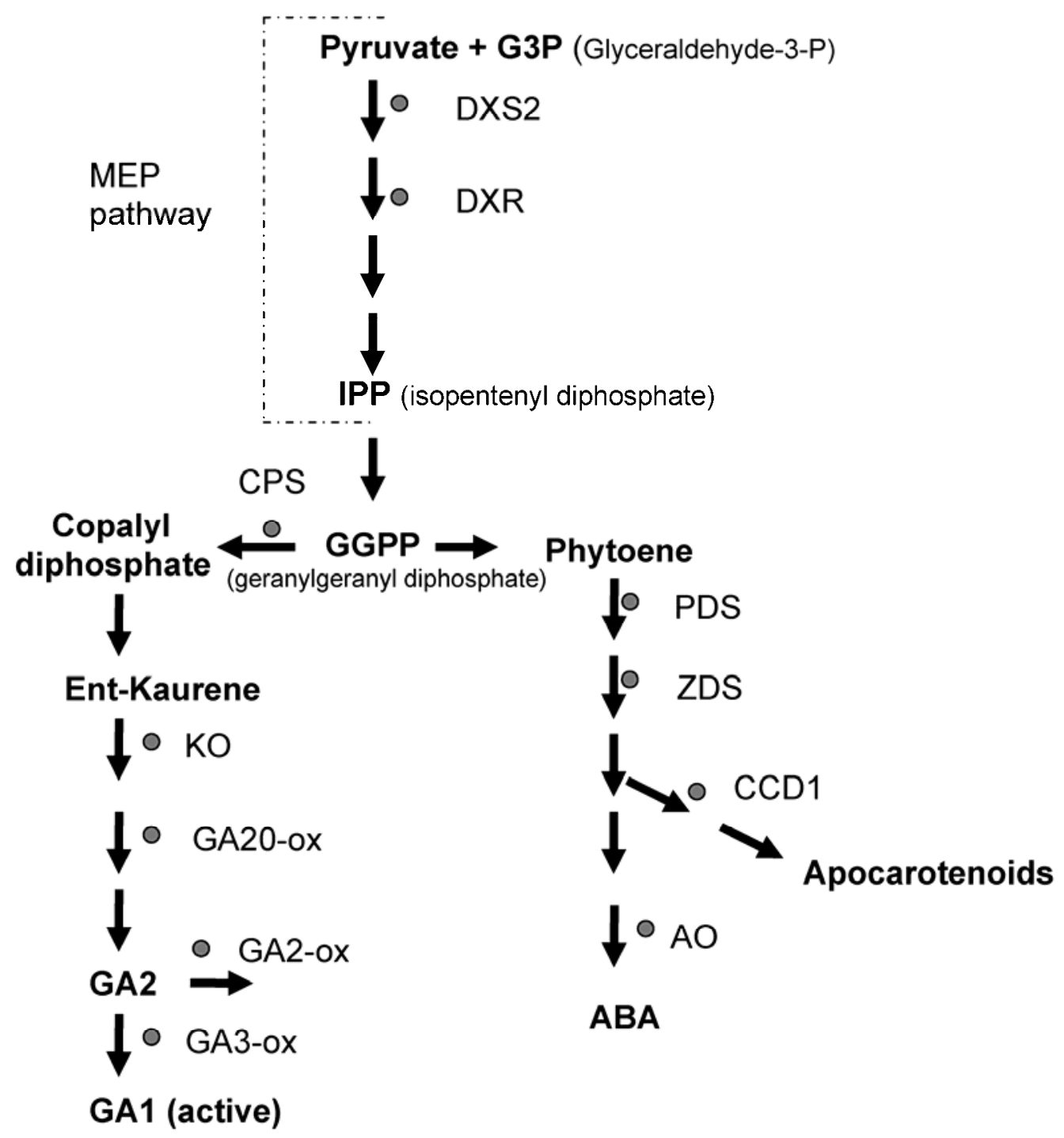

Fig. 2. Simplified pathway of gibberellins (GAs), abscisic acid (ABA), and apocarotenoid biosynthesis. Steps catalyzed by enzymes coded by the upregulated genes identified by the microarray analysis only in wild-type mycorrhizal roots are indicated by a gray circle. MEP = methylerythritol phosphate. Enzyme designations: AO, ABA aldehyde oxidase; CCD, carotenoid cleavage dioxygenase; CPS, ent-copalyl diphosphate synthase; DXR, 1-deoxy-D-xylolose 5-phosphate reductoisomerase; DXS2, 1-deoxy-D-xylulose 5-phosphate synthase 2; GA20-ox1, gibberellin 20-oxidase 1; GA2-ox, gibberellin 2- $\beta$-dioxygenase; GA3-ox, gibberellin 3- $\beta$-dioxygenase; KO, ent-kaurene oxidase; PDS, phytoene desaturase; ZDS, zeta-carotene desaturase. 
pathway-omega-6 fatty acid desaturase (6-Des), lipoxygenase A $(L O X A)$, and allene oxide synthase 3 (AOS3) - showed a similar expression pattern during AM development (Fig. 3C). In wild-type and sitiens plants, the expression of these genes was lower in mycorrhizal than that in nonmycorrhizal plant roots at 37 dai. In mycorrhizal plant roots, the expression of these genes increased from 37 to 56 dai but the expression in wild-type plants always remained lower than in sitiens plants (Fig. 3C).

The results obtained in mutant mycorrhizal plants on the higher expression of genes from the oxylipin pathway (Fig. 3C) differs with the results obtained from the array experiments, in which the expression of these genes was similar in wild-type plants and ABA-deficient mutants inoculated with $G$. intra-

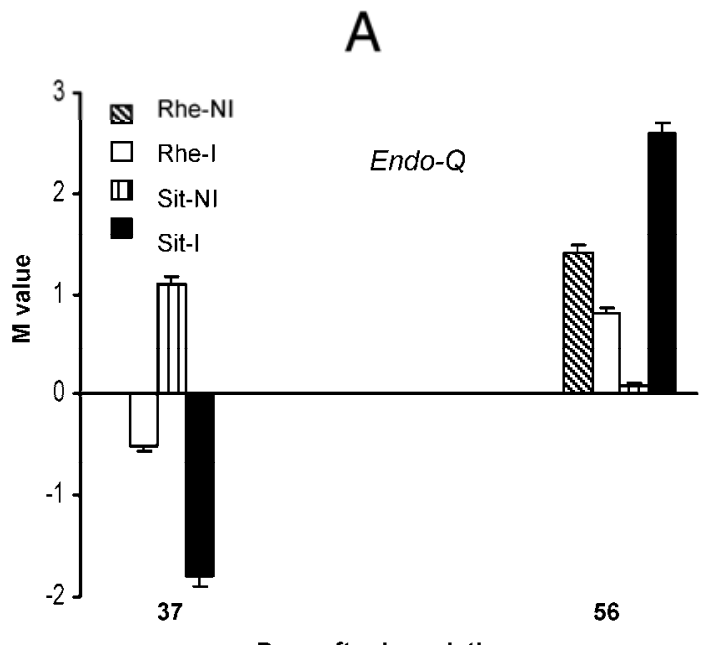

Days after inoculation
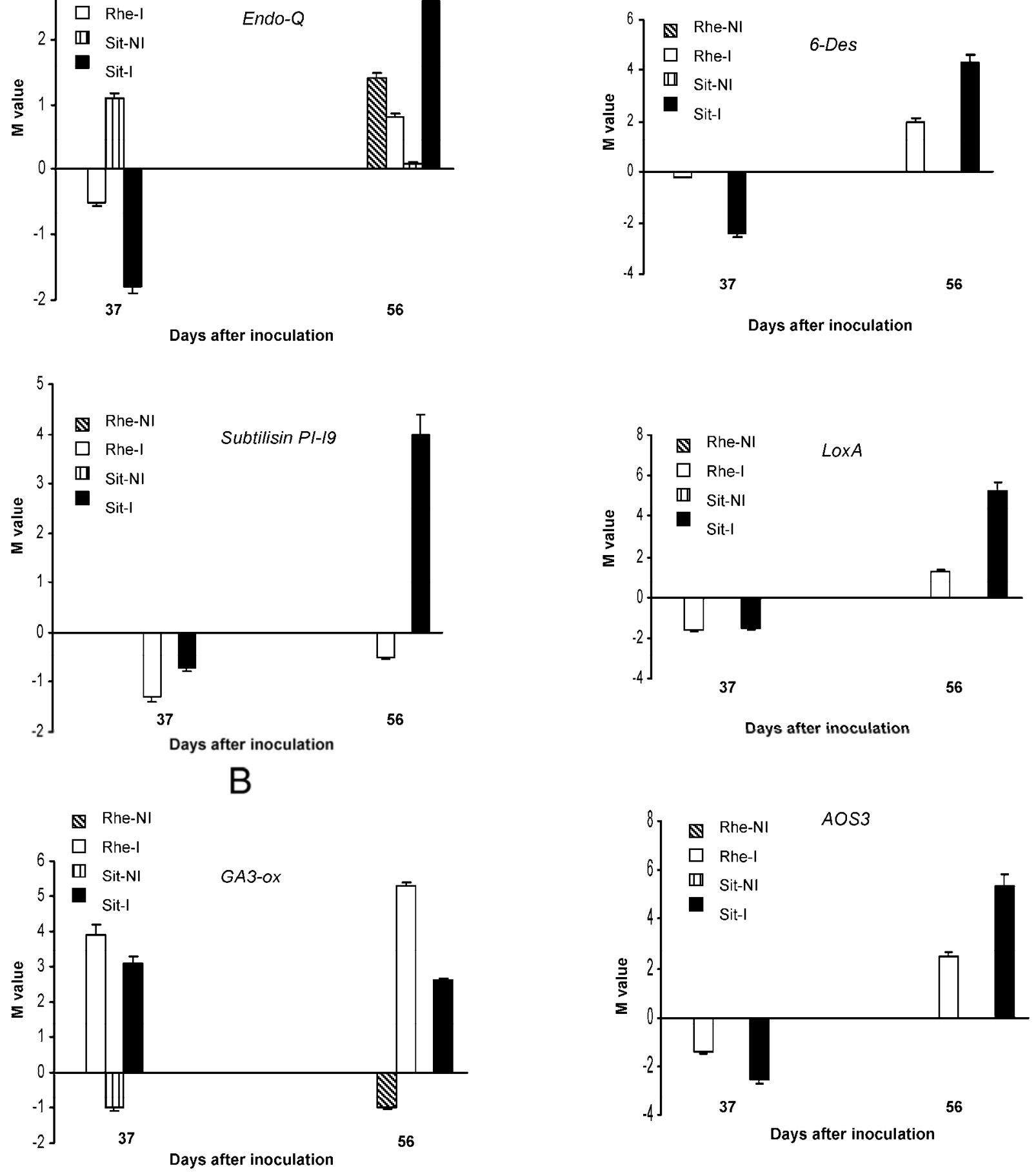

Fig. 3. Expression of representative genes from A, defense; B, gibberellins metabolism; and $\mathbf{C}$, oxylipin pathways during different developmental stages of arbuscular mycorrhiza formation. Quantitative reverse-transcription polymerase chain reaction analysis were performed with cDNA from roots of control noninoculated (NI) and inoculated (I) wild-type (Rhe) and abscisic acid (ABA)-deficient sitiens (Sit) plants at 37 and 56 days after inoculation (dai) with Glomus intraradices. Data represent the $\mathrm{M}$ value ( $\log _{2}$ ratio), which is 0 if there is no change and +1 or -1 if there is a twofold induction or reduction, respectively, compared with the expression of each of the genes in noninoculated wild-type plants at 37 dai. Values are the means \pm standard error of three replications. 
radices. To solve this discrepancy, we quantified the expression of the AOS 3 gene in roots of wild-type and sitiens plants from the three independent experiments of mycorrhization used for the microarray experiments. The comparative analysis of the AOS3 gene expression pattern showed that, in all cases, the expression increased in mycorrhizal plants compared with nonmycorrhizal plants; the expression in wild-type plants remained lower than in sitiens plants only in experiment III. These results support the data of the microarray, validated by qRT-PCR, which represents the average of the information of two experiments (I and II). Wild-type plants from experiment III showed a lower percentage of root colonization and of arbuscules formation and a lower LePT4 transcripts accumulation than wild-type plants from experiments I and II.

To determine the capacity of selected genes to respond to the exogenous application of phytohormone whose content changes in roots of sitiens plants in respect to the wild type, such as ethylene and ABA, tomato plantlets of the wild-type Rheinlands Ruhm cultivar were treated with phytohormone solutions and RNA was extracted from roots after 12 and $24 \mathrm{~h}$ of treatment. We included a treatment with methyl jasmonate (MeJA) due to the importance of the jasmonate signaling pathway during mycorrhization of various plant species (Hause et al. 2007). The experiments were designed only to show the capacity of selected genes to respond to the exogenous application of certain phytohormones, not to determine the exact method of regulation, which may be influenced by developmental and physiological aspects at the different stages of mycorrhiza formation.

ABA treatment caused an upregulation of the $\beta$-Exp gene of sixfold compared with control levels (Fig. 4A). In all, four of the 14 tested genes showed an upregulation by ethylene between three- and 17-fold compared with the control (Fig 4B). From these ethylene-upregulated genes, two of them (AOS3 and $\alpha, \beta$ hydrolase) were found to be upregulated in both wildtype and sitiens mycorrhizal plants (common Myc upregulated genes), and the other two genes were upregulated specifically in sitiens mycorrhizal roots (Endo- $Q$ and $\beta$-Exp). Treatment of plants with MeJA (Fig. 4C) caused higher expression of two genes involved in oxylipin metabolism (AOS3 and LOXA) that are included in the set of the upregulated overlapping genes, and the subtilisin-PI-I9 gene (Les.513.1.S1._at) that was upregulated specifically in sitiens mycorrhizal roots. MeJA caused moderate and transient expression of the RNAse gene and induced late expression of Endo- $Q$ and $\beta$-Exp that are included in the set of genes upregulated in sitiens mycorrhizal roots (Fig. 4C) and were also ethylene-responsive genes (Fig. 4B).

\section{DISCUSSION}

The microarray analysis of transcript profiling of AM symbiosis development in tomato revealed significant changes in gene expression associated with the different mycorrhization status according to the ABA concentration in the roots. As in other mycorrhizal host plants, we identified, in tomato, a set of genes which has already been described as mycorrhizal coreset (Liu et al. 2007; Guether et al. 2009), including genes from protein catabolism, which were mycorrhiza upregulated similarly in wild-type and sitiens plants. Other conserved mycorrhiza-induced genes were protease inhibitor genes, and glucoxyltransferase, annexin, aquaporin-like, cytochrome P450, gibberellin 20-oxidase, and glutathione S-transferase genes, all of whose expression was enhanced mainly in mycorrhiza wildtype plants. These results validate our array data and reinforce the idea of the evolutionary conservation of genetic processes supporting such symbioses. Nevertheless, a limited overlap with a set of mycorrhiza-responsive genes in tomato roots colonized by G. mosseae (Fiorilli et al. 2009) was observed. This could be mainly due to the largely non-overlapping probe sets between the microarray tools used (Affymetrix in the present study and TOM 2 in the work of Fiorilli and associates [2009]), and to the fact that these arrays are only partially representative of the tomato genome. The maximum overlapping $(22 \%)$ was found with the set of genes that exclusively and differentially upregulated in the wild-type tomato plant. Considering that the overall extent of the overlapping between the two platforms was $47 \%$, we calculate, at least hypothetically, an overlapping of approximately $46.2 \%$ between upregulated genes in tomato roots inoculated with $G$. mosseae or $G$. intraradices. Furthermore, others factors such as the fungal species, the different developmental stages of the symbiosis analyzed, and differences in the experimental design between both studies surely contribute to the limited overlap that has been shown.

Although the number of differentially regulated genes was not particularly high in our array experiment, which may be due to the limited number of probe sets contained in the array $(10,209)$, clear differences in gene functional categories between mycorrhizal wild-type and ABA-deficient mutants were obtained.

\section{Oxylipin 9-LOX pathway activation in mycorrhizal roots.}

Oxidative metabolism of polyunsaturated fatty acids gives rise to a group of biologically active compounds, collectively termed oxylipins, which perform a variety of functions in plants (Howe and Schilmiller 2002). The structural and functional diversity among oxylipins is governed by the coordinated expression of specific members of the LOX and cytochrome P450 (CYP74) enzyme families. The relative specificity of these enzymes for either 9- or 13-hydroperoxides supports the concept that oxylipin metabolism is organized into discrete 9-LOX and 13-LOX pathways. In plants, the AOS branch of the 13-LOX pathway transforms 13-hydroperoxy linolenic acid (13-HPOT) to the jasmonate family of compounds that includes JA and MeJA and their metabolic precursor, 12-oxophytodienoic acid (12-OPDA).

Some experimental data support that LOXA and AOS3 (upregulated in our arrays results) are mainly specific for the 9-LOX branch of the oxylipin pathway. The recombinant protein of the LOXA gene has been already investigated, and studies of substrate binding and product stereochemistry have shown that this protein is a linoleate 9S-lipoxygenases (9LOX), similar to the Arabidopsis thaliana LOX1 (Boeglin et al. 2008). Similarly, studies with the recombinant product of the LeAOS3 showed that this enzyme is an AOS active principally against 9-hydroxyperoxides and is distinct from those involved in JA biosynthesis (Itoh et al. 2002).

The expression pattern of the genes from the oxylipin pathway analyzed in the present work indicates that the activation of the 9-LOX pathway in mycorrhizal tomato roots seems to be related to later stages of colonization. The biological significance of the activation of the 9-hydroperoxide-derived oxylipin metabolism in mycorrhizal tomato roots remains unknown; however, some possibilities should be considered. It is conceivable that the 9-LOX pathway plays a defensive role, restricting fungal spread in roots as seen in fungal pathogens (Blée 2002; Vellosillo et al. 2007). The expression of these genes was always increased in mycorrhizal sitiens plants and their expression in mycorrhizal wild-type roots seems to depend on a certain degree of AM-fungal colonization. These findings suggest that the role of these genes could be related to the control of fungal spread in roots and not to the establishment of the symbiosis. In this case, a certain infection threshold should be necessary in wild-type plants to lead a gene expression response. We observed that $L O X A$ and AOS3 transcript 

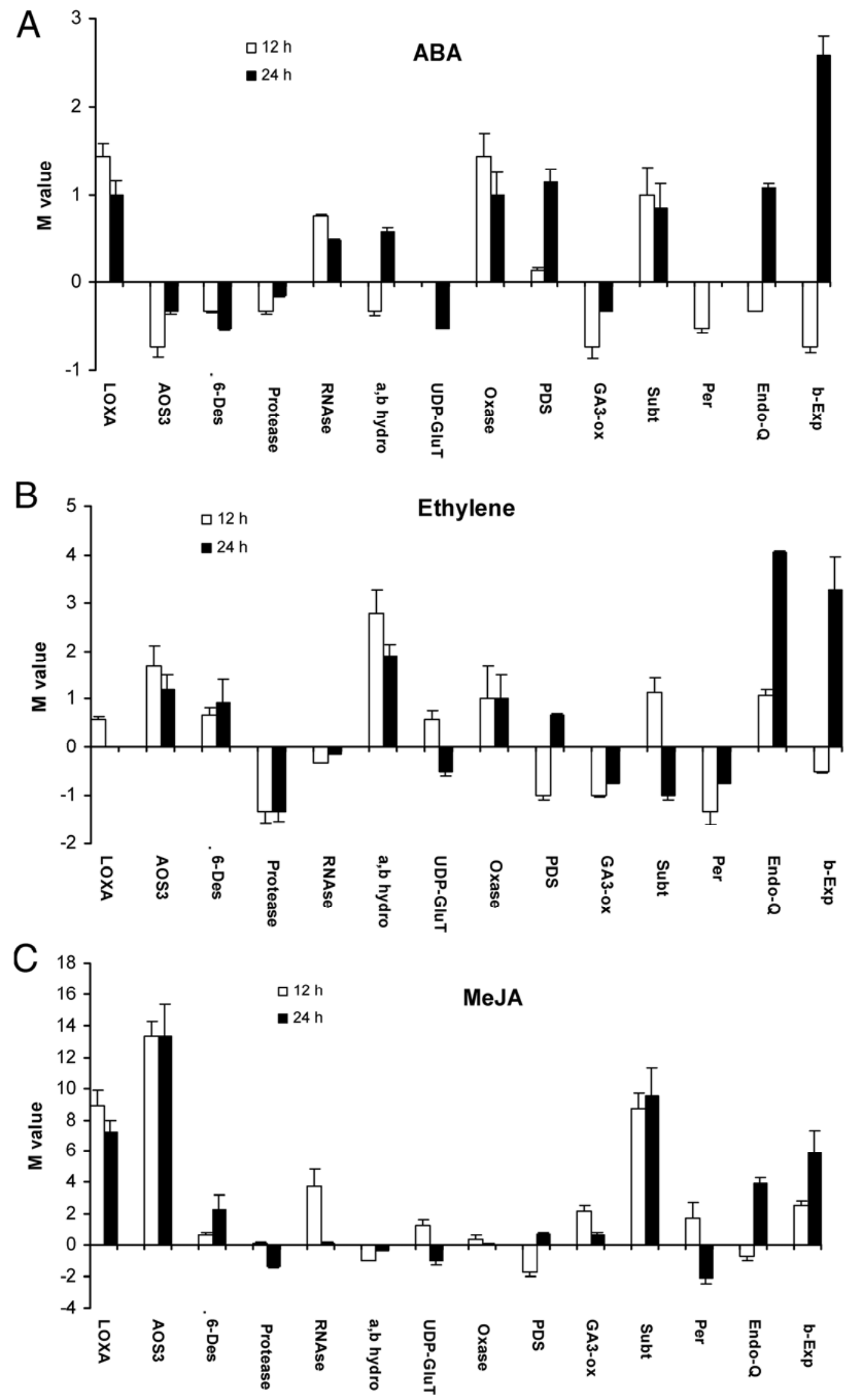

Fig. 4. Phytohormone-induced gene expression of genes with differential expression in mycorrhiza wild-type and abscisic acid (ABA)-deficient sitiens mutant. Quantitative reverse-transcription polymerase chain reaction analyses were performed in 12-day-old tomato plantlets after 12 and $24 \mathrm{~h}$ of $\mathbf{A}$, ABA; $\mathbf{B}$, ethylene; and $\mathbf{C}$, methyl jasmonate (MeJA) treatments. Data represent the $\mathrm{M}$ value ( $\log _{2}$ ratio), which is 0 if there is no change and +1 or -1 if there is a twofold induction or reduction, respectively, compared with the expression of each of the genes in $0.1 \%$ ethanol control. Values are the means \pm standard error of three replications. 
accumulation in roots of tomato seedlings is enhanced by MeJA application, and $A O S 3$ was upregulated by ethylene application. Previous work showed that AOS3 mRNA accumulation is dependent on the JAII gene product that is a component of the jasmonate signaling pathway in tomato (Itoh et al. 2002). In this context, a steady rise of jasmonate was found during mycorrhization of various plant species (Hause et al. 2007) that could regulate the expression of these genes in the stages of maintenance and control of the interaction. The fact that the expression of these genes was always increased in mycorrhizal sitiens plants could be related to the finding that ethylene production was enhanced in ABA-deficient tomato mutants. Moreover, four genes listed in the set of common mycorrhiza-upregulated genes and nonselected in our experiments (Les.3397.2.A1_at, Les.3397.1.S1_at, Les.3281.1.S1_at, and Les.4820.1.S1_x_at) have been identified previously as MeJAresponsive genes ( $\mathrm{Li}$ et al. 2004).

A second possibility is that the 9-LOX pathway activates the production of oxylipins that play a developmental role during root colonization by the arbuscular mycorrhizal fungi. In this respect, some studies provide evidence that products derived form the 9-LOX pathway function as signal molecules for flower, tuber, and lateral root development (Yokoyama et al. 2000; Kolomiets et al. 2001; Vellosillo et al. 2007). However, in a previous work, the increase in JA contrasted with upstream components of the LOX pathway, which were not altered by AM in M. truncatula (Stumpe et al. 2005). Whether the activation of gene expression from genes related to the 9-LOX oxylipin pathway in mycorrhizal tomato roots is emphasized in solanaceous plants and correlated to the accumulation of 9LOX components remains to be elucidated.

\section{Functional mycorrhization in wild-type plants is associated with activation of genes related to carotenoid and gibberellin synthesis.}

Root colonization by arbuscular mycorrhizal fungi usually leads to the accumulation of apocarotenoid compounds in most host plants (Fester et al. 2002, 2005; Strack and Fester 2006). This accumulation occurs preferentially at late stages of the interaction and is accompanied by the upregulation of $D X S 2$ and $D X R$ genes from the MEP pathway that supply IPP and GGPD precursors from which important plant isoprenoids are derived (Walter et al. 2000; Hans et al. 2004). DXS2 was upregulated in mycorrhizal roots (Walter et al. 2002) and genetic approaches have shown local promoter activity of DXS2 in M. truncatula cells hosting fungal arbuscules (Floss et al. 2008a). Strong suppression of DXS2 and carotenoid cleavage dioxygenase 1 ( $C C D 1$ ) expression in $M$. truncatula hairy roots leads to reduced levels of apocarotenoids (Floss et al. 2008a,b) accompanied by an increased proportion of degenerating arbuscules in mycorrhizal roots. However, whereas silencing of $D X S 2$ abolished the expression of typical plant marker genes from AM symbiosis (Floss et al. 2008a), the RNAi-mediated repression of the $M$. truncatula $C C D 1$ gene did not lead to major changes in molecular markers of the AM (Floss et al. $2008 \mathrm{~b}$ ). Whether the increased arbuscule degeneration is linked to the lack of either of these mycorrhizal apocarotenoids in the transgenic $M$. truncatula $D X S 2$ and $C C D 1$ RNAi hairy roots is still unknown.

An important result of our work has been the identification of several genes of the MEP and apocarotenoid pathways in tomato mycorrhizal roots that are homologous to those genes induced in M. truncatula during AM symbiosis. This result confirms the importance of isoprenoid metabolism in mycorrhiza formation. The fact that this group of genes was specifically upregulated in wild-type tomato roots and not in the ABA-deficient mutant suggests that a functional and well-established colonization is nec- essary for their expression in mycorrhizal roots. Previous work has demonstrated that $\mathrm{ABA}$ is essential for mycorrhiza formation and arbuscule development in tomato (Herrera-Medina et al. 2007) and the ABA deficiency in the sitiens mutants leads to an impairment in arbuscule formation and functioning. Sitiens plants are specifically affected in the last step of ABA synthesis and not in any other branch of the isoprenoid metabolism, as with the apocarotenoid strigolactones, which play a role in the early steps of mycorrhizal symbiosis (Akiyama et al. 2005). In fact, sitiens plants are not affected at all in the early signaling steps of mycorrhizal symbiosis (Herrera-Medina et al. 2007). The activation of the synthesis of mycorrhizal apocarotenoids could be a consequence of arbuscule formation. The nonactivation of apocarotenoids synthesis in mycorrhizal sitiens roots may be a consequence of the absence of arbuscule formation.

DXS2 acts in early steps of the MEP pathway, supplying IPP and GGPD precursors from which important plant isoprenoids are derived such as carotenoids, apocarotenoids, ABA, strigolactones, and gibberellins, most of them with relevance in mycorrhizal development and functioning, as has been demonstrated for ABA, strigolactones, and apocarotenoids. In fact, the more relevant conclusion from the comparative analysis of the alterations in the transcript profile in tomato roots as a consequence of G. mosseae colonization (Fiorilli et al. 2009) and the transcriptomic alterations induced by $G$. intraradices colonization of wild-type tomato (this work) is that mycorrhization alters the biosynthesis and catabolism of gibberellins and ABA, suggesting that ABA is involved in arbuscule formation and functioning as previously reported (Herrera-Medina et al. 2007).

Few data exist about the role of gibberellins during AM development, although one study described the negative effect on arbuscule formation of gibberellic acid (GA) application, where a dose-dependent phenomenon of suppression of arbuscule formation was seen in pea plants treated with GA3 (El Ghachtouli et al. 1996). Our data support a direct role for gibberellins during mycorrhization of tomato because at least four different genes related to the metabolism of gibberellins were upregulated in roots of mycorrhizal wild-type tomato. The array results reveal that this group of genes was also specifically upregulated in wild-type tomato roots and not in the ABA-deficient mutant, suggesting that a functional and wellestablished colonization is necessary for their expression in mycorrhizal roots. The analysis of GA3-ox gene expression at different developmental stages of AM formation confirms this suggestion because the maximal expression of GA3-ox correlated with a well-established and functional mycorrhization in wild-type plants. Considering the current results in combination with previous data, it is tempting to speculate that, at least in tomato, three end products of different branches of isoprenoid metabolism-gibberellins, ABA, and apocarotenoidsare necessary for regulating the formation and turnover of arbuscules in host cells.

\section{Upregulation of genes involved in defense and cell wall modification in ABA-deficient mycorrhizal roots.}

It has been proposed that pathogen resistance due to a low ABA content originates from higher, basal defense-related transcript accumulation and subsequent fast, strong defense activation upon pathogen challenge. In fact, the transcript-profiling analysis using TOM1 microarrays revealed that the defense-related transcript accumulation prior to infection of $\mathrm{Bo}$ trytis cinerea was higher in sitiens than in wild-type plants (Asselbergh et al. 2007). Similarly, the comparative analysis of transcriptomic data obtained in mycorrhizal wild-type and ABA-deficient mutant plants revealed that the impairment in $\mathrm{AM}$ formation in ABA-deficient mutants was associated with 
upregulation of genes related to defense and cell wall modification. The upregulation of genes involved in plant cell wall synthesis during AM symbiosis is well documented (Balestrini and Bonfante 2005), and genes for endo-1,4 $\beta$-D-glucanases and cellulose synthase accumulated specifically in the arbusculated cells (Liu et al. 2003; Guether et al. 2009). The products of these genes in conjunction with other proteins probably play a role in cell wall modification and cell expansion during arbuscule formation (Balestrini and Bonfante 2005), and the expression of the related genes should be regulated by the arbuscule morphogenesis.

Our work identified others genes apart from endo-1,4 $\beta$-Dglucanases that may be involved in cell wall loosening and modification, such as extensins, expansins, and pectin enzymes. Interestingly, in our array, these genes appear upregulated in mycorrhizal ABA-deficient roots, probably due to the incomplete arbuscule development that occurs in these plants as a consequence of ABA synthesis impairment (Herrera-Medina et al. 2007). We agree with other authors that cell-wall-modifying genes are upregulated at the beginning of arbuscule formation, leading to the formation of the interface compartment between plant cell and fungal cell plasma membranes. The expression of these genes will probably be downregulated when this interface is formed after arbuscule maturation. In a similar way, during the later stages of mycorrhization, a mechanism of plant defense response activation appears to become stronger, though only in those plant cells which contain fungal arbuscules (García Garrido and Ocampo 2002). The role of defense genes expressed in the cells containing arbuscules could be in the control of hyphal spread and arbuscule formation in the root, and the regulation of the defense gene expression may be regulated by the arbuscule morphogenesis. We hypothesize that the process of arbuscule maturation plays a crucial role in the downregulation of defense and cell-wall-modifying genes. It may be that this downregulation does not take place in $\mathrm{si}$ tiens plants due to an incomplete arbuscule development, as reflected by the array data results, and the data of the comparative analysis of Endo- $Q$ and subtilisin (PI-I9) gene expression at different developmental stages of AM formation in wildtype and sitiens plants. The expression of both genes remained lower in mycorrhizal plants than in nonmycorrhizal plants at the early stage of AM establishment whereas, during the stage of development and maintenance of the interaction, the gene expression only increased in inoculated sitiens plants, unable to form fully functional arbuscules. Nevertheless the exact function of such genes (defense and cell wall related) during mycorrhization is unclear and should be clarified in future studies. Interestingly, the analyzed gene for $\beta$-expansin (LesAffx.5130. 1.S1_at) showed induced expression in response to ABA, ethylene, and MeJA after $24 \mathrm{~h}$ of treatment, and it is tempting to speculate that this result reflects the fine regulation of the extension of the plant cell wall in response to the growing arbuscule in which JA, ABA, and ethylene could be necessary for accommodation of the arbuscule in the cell.

It is well documented that ABA and ethylene mutually antagonize to modulate some plant responses, including disease resistance (Anderson et al. 2004). Moreover, ethylene production was found to be enhanced in ABA-deficient tomato mutants (Hussain et al. 1999) and previous work suggests that ethylene and ABA have antagonistic actions in regulating AM colonization (Herrera-Medina et al. 2007). Given this ABA/ethylene antagonism, it is logical to speculate that the ethylene pathway could have relevance in regulating the expression of genes for defense and cell wall modification, which appear to be the largest functional categories in mycorrhizal ABA-deficient mutants. The results showing the effect of phytohormone treatment on gene expression support this hypothesis because the two selected genes upregulated in the mycorrhized sitiens plants and related to defense (Endo-Q) and cell wall modification ( $\beta$-Exp) were ethylene responsive, and both of them also respond to MeJA.

\section{Conclusions.}

Our microarray analysis comparing mycorrhizal tomato roots of wild-type and ABA-deficient mutant plants allowed us to select a number of genes related to different mycorrhization states according to the ABA concentration in the root. The impairment of AM formation in ABA-deficient mutants is associated with upregulation of genes related to defense and cell wall modification, whereas functional mycorrhization in wildtype plants is associated with activation of genes related to carotene and gibberellin synthesis. The oxylipin pathway was activated in tomato mycorrhizal roots, preferentially at late stages. The results obtained support earlier findings that ethylene and JA are key regulators of gene expression during AM development. When taken together, the results provide new perspectives for studies attempting to discriminate the role of the selected genes during the AM formation.

\section{MATERIALS AND METHODS}

\section{Plant material, growth conditions, and $\mathrm{AM}$ inoculation.}

Seed of Solanum lycopersicum wild-type cv. Rheinlands Ruhm (accession LA0535) and ABA-deficient mutant sitiens (Taylor et al. 1988) (accession LA0575) were obtained from the Tomato Genetics Resource Centre (TGRC) at the University of California. Tomato seed were surface sterilized by soaking in $0.75 \%$ sodium hypochlorite for $5 \mathrm{~min}$, after which they were rinsed with tap water and soaked again in $7 \% \mathrm{H}_{2} \mathrm{O}_{2}$ for $10 \mathrm{~min}$, then rinsed three times with sterile deionized water and germinated on a sterilized moistened filter paper for 3 to 4 days at $25^{\circ} \mathrm{C}$. After germination, plants were grown in a steam-sterilized $\left(40 \mathrm{~min}, 120^{\circ} \mathrm{C}\right)$ mixture of silicate sand, peat, soil, and vermiculite $(1: 1: 1: 1, \mathrm{vol} / \mathrm{vol} / \mathrm{vol} / \mathrm{vol})$. The plant growth and the treatments took place in a growth chamber (day and night cycle of $16 \mathrm{~h}, 25^{\circ} \mathrm{C}$ and $8 \mathrm{~h}, 19^{\circ} \mathrm{C}$, respectively; relative humidity, $50 \%$ ). Every day, sitiens plants were sprayed with water to prevent plants from wilting.

The inoculation with $G$. intraradices (DAOM 197198), reclassified as G. irregulare according to Stockinger and associates (2009), was carried out in 200-ml pots. Each seedling was grown in a separate pot and was inoculated with a piece of monoxenic culture in Gel-Gro medium containing 50 spores of $G$. intraradices and infected carrot roots. The monoxenic culture ( $G$. intraradices and carrot roots) was made according to Chabot and associates (1992). In the noninoculated treatment, the plants were inoculated with a piece of Gel-Gro medium containing only uninfected carrot roots. One week after planting in pots and weekly thereafter, the pots were given $20 \mathrm{ml}$ of a modified Long Ashton nutrient solution containing $25 \%$ of the P concentration (Hewitt 1966) to prevent mycorrhizal inhibition due to excess of P. Plants were harvested 50 days after inoculation, and the root system was washed and rinsed several times with sterilized distilled water. The root system was weighed and used for the different measurements according to the nature of the experiments. In each experiment, five independent plants were analyzed per treatment. Three different experiments of AM inoculation were performed to obtain material for three biological replicates for each condition.

Some root segments were stained using the nonvital trypan blue histochemical staining procedure according to the method of Phillips and Hayman (1970). Stained roots were observed with a light microscope and the intensity of root cortex colonization and arbuscular abundance in mycorrhizal roots fragments 
(percent) was determined as described by Trouvelot and associates (1986) using mycocalc software. In some cases, mycorrhization was evaluated by the grid-line intersect method described by Giovannetti and Mosse (1980).

RNA isolation, synthesis of biotinylated cRNA, and hybridization, washing, and scanning of microarrays.

Plant roots were harvested and immediately frozen in liquid nitrogen in a 2-ml reaction tube. Plant material was ground to a fine powder with a mortar and total RNA was isolated using the RNeasy Plant Mini Kit (Qiagen, Gaithersburg, MD, U.S.A.) following the manufacturer's instructions. Genomic DNA was removed and each RNA preparation was tested for degradation using the Agilent 2100 Bioanalyzer (Agilent Technologies, Palo Alto, CA, U.S.A.). cDNA was synthesized from $4 \mu \mathrm{g}$ of total RNA using one-cycle target labeling and control reagents (Affymetrix, Santa Clara, CA, U.S.A.) to produce biotin-labeled cRNA. The cRNA preparations $(15 \mu \mathrm{g})$ were fragmented at $94^{\circ} \mathrm{C}$ for 35 min into 35 to 200 bases in length.

Three biological replicates for each condition were independently hybridized. If the quality control was correct, then $10 \mu \mathrm{g}$ of fragmented cRNA was hybridized to the GeneChip Tomato Genome Array (Affymetrix), containing over 10,000 S. lycopersicum probe sets to interrogate over 9,200 S. lycopersicum transcripts.

Each sample was added to a hybridization solution containing $100 \mathrm{mM}$ 2-(N-morpholino) ethanesulfonic acid, $1 \mathrm{M} \mathrm{Na}^{+}$, and $20 \mathrm{mM}$ EDTA in the presence of $0.01 \%$ Tween-20 to a final cRNA concentration of $0.05 \mu \mathrm{g} / \mathrm{ml}$. Hybridization was performed for $16 \mathrm{~h}$ at $45^{\circ} \mathrm{C}$. Each microarray was washed and stained with streptavidin-phycoerythrin in a Fluidics station 450 (Affymetrix) and scanned at $1.56-\mu \mathrm{m}$ resolution in a GeneChip Scanner 3000 7G System (Affymetrix). Data analyses were performed using GeneChip Operating Software.

\section{Data analysis.}

Analysis was performed using the affylmaGUI R package (Wettenhall et al. 2006). The robust multi-array analysis algorithm was used for background correction, normalization, and expression levels summarization (Irizarry et al. 2003). Next, differential expression analysis was performed with the Bayes $t$ statistics from the linear models for Microarray data (limma), included in the affylmGUI package. $P$ values were corrected for multiple testing using the Benjamini-Hochberg method (false discovery rate) (Benjamini and Hochberg 1995; Reiner et al. 2003). Genes were considered to be differentially expressed if the corrected $P$ values were $<0.05$. In addition, only genes with a signal $\log$ ratio $>1$ or $<-1$ were considered for further analysis. Graphical visualization of data was performed with the interactive tool FIESTA.

Microarray data have been deposited in ArrayExpress as accession E-MEXP-2356.

\section{cDNA synthesis and $q R T-P C R$ conditions.}

cDNAs were obtained from $1 \mu \mathrm{g}$ of total DNAse-treated RNA in a $20-\mu 1$ reaction volume using the iScript cDNA synthesis kit, following the protocol of the supplier (Bio-Rad, Hercules, CA, U.S.A.). qRT-PCR was carried out with an iCycler apparatus (Bio-Rad). Each 20- $\mu$ l PCR reaction contained 1 $\mu \mathrm{l}$ of diluted cDNA (1:10), $10 \mu \mathrm{l}$ of $2 \times$ SYBR Green Supermix (Bio-Rad), and $200 \mathrm{nM}$ each primer using a 96-well plate. The PCR program consisted of a 3-min incubation at $95^{\circ} \mathrm{C}$ followed by 35 cycles of $30 \mathrm{~s}$ at $95^{\circ} \mathrm{C}, 30 \mathrm{~s}$ at 58 to $63^{\circ} \mathrm{C}$, and 30 $\mathrm{s}$ at $72^{\circ} \mathrm{C}$. The specificity of the PCR amplification procedure was checked with a melting curve after the final cycle of the PCR (70 steps of $30 \mathrm{~s}$ from 60 to $95^{\circ} \mathrm{C}$ with a heating rate of $\left.0.5^{\circ} \mathrm{C}\right)$.
Primers were designed using Primer-BLAST and Primer3 online applications. Oligonucleotides were checked to avoid nonspecific product formation using a free NetPrimer software application. Amplicons were analyzed for potential secondary structures using the Mfold method. All the primers that were used are listed in supporting information (Supplementary Table S3).

Real-time PCR experiments were carried out from two biological replicates and the threshold cycle $\left(\mathrm{C}_{\mathrm{T}}\right)$ was determined in triplicate. The relative levels of transcription were calculated by using the $2^{-\Delta \Delta \mathrm{CT}}$ method (Livak and Schmittgen 2001). $\mathrm{C}_{\mathrm{T}}$ values of all genes were normalized to the $C_{T}$ value of the LeEF-1 (X14449) housekeeping gene.

\section{Phytohormone treatment.}

Tomato plantlets (Rheinlands Ruhm) were treated with 50 $\mu \mathrm{M}$ ABA (Sigma-Aldrich, Steinheim, Germany), $50 \mu \mathrm{M}$ methyl jasmonate (MeJA) (Sigma-Aldrich), or $70 \mu \mathrm{M}$ Ethephon (Sigma-Aldrich). After germination, tomato plantlets were grown hydroponically in half-diluted Hewitt solution (Hewitt 1966) for 11 days; then, the plant root systems were washed in water and plants were conditioned during $24 \mathrm{~h}$ in 14-cm-diameter plates containing filter paper soaked in distilled water. After this time, filter papers were replaced by others soaked in chemical solutions. Plants were harvested 12 and $24 \mathrm{~h}$ later and the root system was washed and immediately frozen in liquid nitrogen.

The aqueous stock solution of MeJA contains $1 \mathrm{mM}$ MeJA and $0.01 \%$ Tween 20. Stock solution of ABA contained $1 \mathrm{mM}$ ABA in $1 \%$ ethanol solution, and stock solution of ethephon was prepared at $1 \mathrm{mM}$ in water. Control plantlets were treated with $0.1 \%$ ethanol solution. The $\mathrm{pH}$ of each solution was adjusted to 7 prior to use.

\section{ABA quantification.}

For ABA quantification, freeze-dried roots (the equivalent of minimum $100 \mathrm{mg}$, fresh weight, of root material) was extracted with a mixture of isopropanol and acetic acid (95:5, vol/vol). To each sample, $100 \mathrm{ng}$ of $\left(\mathrm{d}_{6}\right)$-ABA (Plant Biotechnology Institute, National Research Council of Canada, Saskatoon, Canada) was added. Sample preparation was performed according to Meixner and associates (2005), and methylation was carried out according to Cohen (1984) with freshly prepared diazomethane. Gas chromatography-mass spectrometry analysis was carried out on a Varian Saturn 2100 ion-trap mass spectrometer using electron impact ionization at $70 \mathrm{eV}$, connected to a Varian CP3900 gas chromatograph equipped with a CP-8400 autosampler (Varian, Walnut Creek, CA, U.S.A.). For the analysis, $2 \mu \mathrm{l}$ of the methylated sample dissolved in $30 \mu \mathrm{l}$ of ethyl acetate was injected in the splitless mode (splitter opening 1:100 after $1 \mathrm{~min}$ ) onto a Phenomenex (Aschaffenburg, Germany) ZB-5 column (30 $\mathrm{m}$ by $0.25 \mathrm{~mm}$ by $0.25 \mu \mathrm{m}$ ) using $\mathrm{He}$ carrier gas at $1 \mathrm{ml}$ $\mathrm{min}^{-1}$. Injector temperature was $250^{\circ} \mathrm{C}$ and the temperature program was $60^{\circ} \mathrm{C}$ for $1 \mathrm{~min}$, followed by an increase of $25^{\circ} \mathrm{C}$ $\min ^{-1}$ to $180^{\circ} \mathrm{C}, 5^{\circ} \mathrm{C} \mathrm{min}^{-1}$ to $250^{\circ} \mathrm{C}, 25^{\circ} \mathrm{C} \mathrm{min}^{-1}$ to $280^{\circ} \mathrm{C}$, then 5 min isothermically at $280^{\circ} \mathrm{C}$. The methyl ester of ABA eluted under these conditions at $13.5 \mathrm{~min}$. For higher sensitivity, the $\mu$ SIS mode (Varian Manual) (Wells and Huston 1995) was used.

The endogenous ABA concentration was calculated by the principles of isotope dilution using the ions of the methylated substance at $\mathrm{m} / \mathrm{z}$ 190/194 (ions deriving from endogenous and d6-ABA) (Walker-Simmons et al. 2000).

\section{ACKNOWLEDGMENTS}

We thank J. Ludwig-Müller from the Institut für Botanik, Technische Universität Dresden, where the experiments of ABA quantification were 
carried out; the tomato genetics resource centre (TGRC) at the University of California for providing sitiens tomato seed; M. I. Tamayo and $\mathrm{N}$. Molinero for help with plant experiments; $\mathrm{H}$. Vierheilig for critical reading of the manuscript; and The Genomics Unit at the CNB (CSIC), where the experiments of GeneChip hybridization were carried out. Financial support for this study was provided by the Ministerio de Ciencia e Innovación (MICINN), Spain (AGL2005-0639; AGL2008-00742/AGR). R. J. León and J. A. Martín are supported by grants from the CSIC and the MICINN, respectively.

\section{LITERATURE CITED}

Akiyama, K., Matsuzaki, K., and Hayashi, H. 2005. Plant sesquiterpenes induce hyphal branching in arbuscular mycorrhizal fungi. Nature 435:824-827.

Anderson, J. P., Badruzsaufari, E., Schenk, P. M., Manners, J. M., Desmond, O. J., Ehlert, C., Maclean, D. J., Ebert, P. R., and Kazan, K. 2004. Antagonistic interaction between abscissic acid and jasmonate-ethylene signaling pathways modulates defense gene expression and disease resistance in Arabidopsis. Plant Cell 16:3460-3479.

Asselbergh, B., Curvers, K., Francxa, S. C., Audenaert, K., Vuylsteke, M., Van Breusegem, F., and Höfte, M. 2007. Resistance to Botrytis cinerea in sitiens, an abscissic acid-deficient tomato mutant, involves timely production of hydrogen peroxide and cell wall modifications in the epidermis. Plant Physiol. 144:1863-1877.

Balestrini, R., and Bonfante, P. 2005. The interface compartment in arbuscular mycorrhizae: A special type of plant cell wall? Plant Biosyst. 139:8-15.

Banba, M., Gutjahr, C., Miyao, A., Hirochika, H., Paszkowski, U., Kouchi, H., and Imazumi-Anraku, H. 2008. Divergence of evolutionary ways among common sym genes: CASTOR and CCaMK show functional conservation between two symbiosis systems and constitute the root of a common signaling pathway. Plant Cell Physiol. 49:1659-1671.

Benjamini, Y., and Hochberg, Y. 1995. Controlling the false discovery rate: A practical and powerful approach to multiple testing. J. R. Stat. Soc. B 57:289-300

Blée, E. 2002. Impact of phyto-oxylipins in plant defense. Trends Plant Sci. 7:315-322.

Boeglin, W. E., Itoh, A., Zheng, Y., Coffa, G., Howe, G. A., and Brash, A. R. 2008. Investigation of substrate binding and product stereochemistry issues in two linoleate 9-lipoxygenases. Lipids 43:979-987.

Chabot, C., Bécard, G., and Piché, Y. 1992. Life cycle of Glomus intraradix in root organ culture. Mycologia 84:315-321.

Chen, C., Gao, M., Liu, J., and Zhu, H. 2007. Fungal symbiosis in rice requires an ortholog of a legume common symbiosis gene encoding a $\mathrm{Ca}^{+} /$calmodulin-dependent protein kinase. Plant Physiol. 145:16191628.

Chen, C., Ane, J. M., and Zhu, H. 2008. OsIPD3, an ortholog of the Medicago truncatula DMI3 interacting protein IPD3, is required tor mycorrhizal symbiosis in rice. New Phytol. 156:311-315.

Cohen, J. D. 1984. Convenient apparatus for the generation of small amounts of diazomethane. J. Chromatogr. 303:193-196.

Deguchi, Y., Banba, M., Shimoda, Y., Chechetka, S. A., Suzuri, R., Okusako, Y., Ooki, Y., Toyokura, K., Suzuki, A., Uchiumi, T., Higashi, S., Abe, M., Kouchi, H., Izui, K., and Hata, S. 2007. Transcriptome profiling of Lotus japonicus roots during arbuscular mycorrhiza development and comparison with that of nodulation. DNA Res. 14:117-133.

El Ghachtouli, N., Martin-Tangury, J., Paynot, M., and Gianinazzi, S. 1996. First report of the inhibition of arbuscular mycorrhizal infection of Pisum sativum by specific and irreversible inhibition of polyamine biosynthesis or by gibberellic acid treatment. FEBS (Fed. Eur. Biochem. Soc.) Lett. 385:189-192.

Fester, T., Schmidt, D., Lohse, S., Walter, M. H., Giuliano, G., Bramley, P. M., Fraser, P. D., Hause, B., and Strack, D. 2002. Stimulation of carotenoid metabolism in arbuscular mycorrhizal roots. Planta 216:148-154.

Fester, T., Wray, V., Nimtz, M., and Strack, D. 2005. Is stimulation of carotenoid biosynthesis in arbuscular mycorrhizal roots a general phenomenon? Phytochemistry 66:1781-1786.

Fiorilli, V., Catoni, M., Miozzi, L., Novero, M., Accotto, G. P., and Lanfranco, L. 2009. Global and cell-type gene expression profiles in tomato plants colonized by an arbuscular mycorrhizal fungus. New Phytol. doi:10.1111/j.1469-8137.2009.03031.x

Floss, D., Hause, B., Lange, P. R., Küster, H., Strack, D., and Walter, M. H. 2008a. Knock-down of the MEP pathway isogene 1-deoxy-D-xylolose 5-phosphate synthase 2 inhibits formation of arbuscular mycorrhiza-induced apocarotenoids, and abolishes normal expression of mycorrhiza-specific plant marker genes. Plant J. 56:86-100.

Floss, D., Schliemann, W., Schmidt, J., Strack, D., and Walter, M. H. 2008b. RNA interference-mediated repression of $M t C C D 1$ in mycorrhi- zal roots of Medicago truncatula causes accumulation of $\mathrm{C}_{27}$ apocarotenoids, shedding light on the functional role of CCD1. Plant Physiol. 148:1267-1282.

García-Garrido, J. M., and Ocampo, J. A. 2002. Regulation of the plant defence response in arbuscular mycorrhizal symbiosis. J. Exp. Bot. 53:1377-1386.

Giovannetti, M., and Mosse, B. 1980. An evaluation of techniques for measuring vesicular arbuscular mycorrhizal infection in roots. New Phytol. 84:489-500.

Godfroy, O., Debelle, F., Timmer, T., and Rosenberg, C. 2006. A rice calcium-calmodulin dependent kinase restores nodulation to a legume mutant. Mol. Plant-Microbe Interact. 19:495-501.

Gomez, S. K., Javot, H., Deewatthanawong, P., Torres-Jerez, I., Tang, Y, Blancaflor, E. B., Udvardi, M. K., and Harrison, M. J. 2009. Medicago truncatula and Glomus intraradices gene expression in cortical cells harboring arbuscules in the arbuscular mycorrhizal symbiosis. BMC Plant Biol. 9:10.

Grunwald, U., Guo, W., Fischer, K., Isayenkov, S., Ludwing-Müller, J., Hause, B., Yan, X., Küster, H., and Franken, F. 2009. Overlapping expression patterns and differential transcript levels of phosphate transporter genes in arbuscular mycorrhizal, Pi-fertilised and phytohormonetreated Medicago truncatula roots. Planta 229:1023-1034.

Guether, M., Balestrini, R., Hannah, M., He, J., Udvardi, M. K., and Bonfante. P. 2009. Genome-wide reprogramming of regulatory networks, transport, cell wall and membrane biogenesis during arbuscular mycorrhizal symbiosis in Lotus japonicus. New Phytol. 182:200-212.

Güimil, S., Chang, H.-S., Zhu, T., Sesma, A., Osbourn, A., Roux, C., Loannidis, V., Oakeley, E. J., Docquier, M., Descombes, P., Briggs, S. P., and Paszkowski, U. 2005. Comparative transcriptomics of rice reveals an ancient pattern of response to microbial colonization. Proc. Natl. Acad. Sci. U.S.A. 102:8066-8070.

Gutjahr, C., Banba, M., Croset, V., An, K., Miyao, A., An, G., Hirochika, H., Imaizumi-Anraku, H., and Paszokowski, U. 2008. Arbuscular mycorrhiza-specific signaling in rice transcends the common symbiosis signaling pathway. Plant Cell 20:2989-3005.

Hans, J., Hause, B., Fester, T., Strack, D., and Walter, M. H. 2004. Cloning, characterization and immunolocalization of a mycorrhizal-inducible 1-deoxy-d-xylolose 5-phosphate isomerase in arbuscule-containing cells of maize. Plant Physiol. 134:614-624.

Hause, B., Mrosk, C., Isayenkov, S., and Strack, D. 2007. Jasmonates in arbuscular mycorrhizal interactions. Phytochemistry 8:101-110.

Herde, O., Peña-Cortés, H., Wasternack, C., Willmitzer, L., and Fisahn, J. 1999. Electric signaling and Pin2 gene expression on different abiotic stimuli depend on a distinct threshold of endogenous abscissic acid in several abscissic acid-deficient tomato mutants. Plant Physiol. 119:213218.

Herrera-Medina, M. J., Steinkellner, S., Vierheilig, H., Ocampo, J. A., and García Garrido, J. M. 2007. Abscissic acid determines arbuscule development and functionality in the tomato arbuscular mycorrhiza. New Phytol. 175:554-564.

Herrera-Medina, M. J., Tamayo, M. I., Vierheilig, H., Ocampo, J. A., and García Garrido, J. M. 2008. The jasmonic acid signalling pathway restricts the development of the arbuscular mycorrhizal association in tomato. J. Plant Growth Regul. 27:221-230.

Hewitt, E. J. 1966. Sand water culture methods used in the study of plant nutrition. Commonwealth Agriculture Bureau Technical Communication No. 22. 2nd ed. Commonwealth Agricultural Bureaux, Frankam Royal, Bucks, England.

Hohnejc, N., Vieweg, M. E., Puhler, A., Becker. A., and Kuster, H. 2005. Overlaps in the transcriptional profiles of Medicago truncatula roots inoculated with two different Glomus fungi provide insights into the genetic program activated during arbuscular mycorrhiza. Plant Physiol. 137:1283-1301.

Howe, G. A., and Schilmiller, A. L. 2002. Oxylipin metabolism in response to stress. Curr. Opin. Plant Biol. 5:230-236.

Hussain, A., Roberts, J. A., Black, C. R., and Taylor, I. B. 1999. Soil compaction: Is there an ABA-ethylene relationship regulating leaf expansion in tomato? Pages 187-188 in: Biotechnology of the Plant Hormone Ethylene II. A. K. Kanellis, C. Chang, H. Klee, A. B. Bleeker, J. C. Pech, and D. Grierson, eds. Kluwer Academic Publishers, Dordrecht, The Netherlands.

Irizarry, R. A., Hobbs, B., Collin, F., Beazer-Barclay, Y. D., Antonellis, K. J., Scherf, U., and Speed, T. P. 2003. Exploration, normalization, and summaries of high density oligonucleotide array probe level data. Biostatistics 4:249-264.

Isayenkov, S., Mrosk, C., Stenzel, I., Strack, S., and Hause, B. 2005. Suppression of allene oxide cyclase in hairy roots of Medicago truncatula reduces jasmonate levels and the degree of mycorrhization with Glomus intraradices. Plant Physiol. 139:1401-1410.

Itoh, A., Schilmiller, A. L., McCaig, B. C., and Howe, G. A. 2002. Identifi- 
cation of a jasmonate-regulated allene oxide synthase that metabolizes 9-hydroperoxides of linoleic and linolenic acids. J. Biol. Chem. 277:46051-46058.

Kistner, C., Winzer, T., Pitzschke, A., Mulder, L., Sato, S., Kaneko, T. Tabata, S., Sandal, N., Stougaard, J., Webb, K. J., Szczyglowski. K., and Parniske, M. 2005. Seven Lotus japonicus genes required for transcriptional reprogramming of the root during fungal and bacterial symbiosis. Plant Cell 17:2217-2229.

Kolomiets, M. V., Hannapel, D. J., Chen, H., Tymeson, M., and Gladon, R. J. 2001. Lipoxygenase is involved in the control of potato tuber development. Plant Cell 13:613-626.

Li, L., Zhao, Y., McCaig, B. C., Wingerd, B. A., Wang, J., Whalon, M. E., Pichersky, E., and Howe, A. 2004. The tomato homolog of CORONATINE-INSENSITIVE 1 is required for the maternal control of seed maturation, jasmonate-signalling defense responses, and glandular thichome development. Plant Cell 16:126-143.

Liu, J. Y., Blaylock, L. A., Endre, G., Cho, J., Town, C. D., VandenBosch, K. A., and Harrison, M. J. 2003. Transcript profiling coupled with spatial expression analyses reveals genes involved in distinct developmental stages of an arbuscular mycorrhizal symbiosis. Plant Cell 15:21062123.

Liu, J. Y., Maldonado-Mendoza, I., Lopez-Meyer, M., Cheung, F., Town, C. D., and Harrison, M. J. 2007. Arbuscular mycorrhizal symbiosis is accompanied by local and systemic alterations in gene expression and an increase in disease resistance in the shoots. Plant J. 50:529-544.

Livak, K. J., and Schmittgen, T. D. 2001. Analysis of relative gene expression data using real-time quantitative PCR and the $2^{-\Delta \Delta \mathrm{Ct}}$ method. Methods 25:402-408.

Meixner, C., Ludwig-Müller, J., Miersch, O., Gresshoff, P., Staehelin, C., and Vierheilig, H. 2005. Lack of mycorrhizal autoregulation and phytohormonal changes in the supernodulating soybean mutant nts1007. Planta 222:709-715.

Okuley, J., Lightner, J., Feldmann, K., Yadav, N., Lark, E., and Browse, J. 1994. Arabidopsis FAD2 gene encodes the enzyme that is essential for polyunsaturated lipid synthesis. Plant Cell 6:147-158.

Parniske, M. 2004. Molecular genetics of the arbuscular mycorrhizal symbiosis. Curr. Opin. Plant Biol. 7:414-421.

Parniske, M. 2008. Arbuscular mycorrhiza: The mother of plant root endosymbioses, Nat. Rev. Microbiol. 6:763-775.

Phillips, J. M., and Hayman, D. S. 1970. Improved procedures for clearing roots and staining parasitic and vesicular-arbuscular mycorrhizal fungi for rapid assessment of infection. Trans. Br. Mycol. Soc. 55:158-161.

Reiner, A., Yekutieli, D., and Benjamini, Y. 2003. Identifying differentially expressed genes using false discovery rate controlling procedures. Bioinformatics 19:368-375.

Stockinger, H., Walker, C., and Schüßler, A. 2009. 'Glomus intraradices DAOM197198', a model fungus in arbuscular mycorrhiza research, is not Glomus intraradices. New Phytol. 183:1176-1187.

Strack, D., and Fester, T. 2006. Isoprenoid metabolism and plastid reorganization in arbuscular mycorrhizal roots. New Phytol. 172:22-34.

Stumpe, M., Carsjens, J.-G., Stenzel, I., Gobel, C., Lang, I., Pawlowski, K., Hause, B., and Feussner, I. 2005. Lipid metabolism in arbuscular mycorrhizal roots of Medicago truncatula. Phytochemistry 66:781-791.

Taylor, I. B., Linforth, R. S. T., Al-Naieb, R. J., Bowman, W. R., and Marples, B. A. 1988. The wilty tomato mutants flacca and sitiens are impaired in the oxidation of ABA-aldehyde to ABA. Plant Cell Environ.
11:739-745.

Trouvelot, A., Kough, J. L., and Gianinazzi-Pearson, V. 1986. Mesure du taux de mycorrhization VA d'un système radiculaire. Recherche de methods d'estimation ayant une signification fonctionelle. Pages 217 221 in: Physiological and Genetical Aspects of Mycorrhizae. V. Gianinazzi-Pearson and S. Gianinazzi, eds. Institut National de la Recherche Agronomique, Paris.

Vellosillo, T., Martínez, M., López, M. A., Vicente, J., Cascón, T., Dolan, L., Hamberg, M., and Castresana, C. 2007. Oxylipins produced by the 9-lipoxygenase pathway in Arabidopsis regulate lateral root development and defense responses through a specific signaling cascade. Plant Cell 19:831-846.

Walker-Simmons, M. K., Rose, P. A., Hogge, L. R., and Abrams, S. R. 2000. Abscissic acid: ABA immunoassay and gas chromatography/mass spectrometry verification. Pages 33-47 in: Methods in Molecular Biology, Vol. 141: Plant Hormone Protocols. G. A. Tucker and J. A. Roberts, eds. Humana Press Inc., Totowa, NJ, U.S.A.

Walter, M. H., Fester, T., and Strack, D. 2000. Arbuscular mycorrhizal fungi induce the non-mevalonate methyletythritol phosphate pathway of isoprenoid biosynthesis correlated with the accumulation of the "yellow pigment" and other apocarotenoids. Plant J. 21:571-578.

Walter, M. H., Hans, J., and Strack, D. 2002. Two distantly related genes encoding 1-deoxy-D-xylulose 5-phosphate synthases: Differential regulation in shoots and apocarotenoid-accumulating mycorrhizal roots. Plant J. 31: 243-254.

Wells, G., and Huston, C. 1995. High-resolution selected ion monitoring in a quadrupole ion trap mass spectrometer. Anal Chem. 67:3650-3655.

Wettenhall, J. M., Simpson, K. M., Satterley, K., and Smith, G. K. 2006. affylmGUI: A graphical user interface for linear modeling of single channel microarray data. Bioinformatics 22:897-899.

Yokoyama, M., Yamaguchi, S., Inomata, S., Komatsu, K., Yoshida, S., Ida, T., Yokokawa, Y., Yamaguchi, M., Kaihara, S., and Takimoto, A. 2000 Stress-induced factor involved in flower formation of Lemna is an $\alpha$ ketol derivate of linolenic acid. Plant Cell Physiol. 42:110-113.

\section{AUTHOR-RECOMMENDED INTERNET RESOURCES}

Affymetrix NetAffxAnalysis Center webpage: www.affymetrix.com/analysis/index.affx

ArrayExpress website: www.ebi.ac.uk/microarray-as/ae

BioinfoGP FIESTAserver: bioinfogp.cnb.csic.es/tools/FIESTA

Cornell University's Tomato functional genome database: ted.bti.cornell.edu/

Cornell University's Tomato functional genomics database array probe annotation page: ted.bti.cornell.edu/cgi-bin/TFGD/array/download_annotation.cgi

Mychintec website: www.dijon.inra.fr/mychintec

The National Center for Biotechnology Information Primer-BLAST website: www.ncbi.nlm.nih.gov/tools/primer-blast/

PREMIER Biosoft NetPrimer software webpage: www.premierbiosoft.com/

Primer3 webpage: frodo.wi.mit.edu/primer3

The Rensselaer bioinformatics web server: www.bioinfo.rpi.edu/applications/mfold

Sol Genomics Network (SGN Blast): sgn.cornell.edu/tools/blast 